managed. We pulled into our original stop nearly three hours after our first fateful move. My patient punched the air and leapt off. I felt like I had just stepped out of a film.

I called him the next day to check his reaction to this extraordinary day. He said he felt proud and amazed and had just had a hearty breakfast; the first one in years. He sounded bold and bright.
Flooding as a therapeutic technique is currently out of favour, mostly on ethical grounds. Graded exposure is seen as a much more patient-friendly behavioural approach. However, no matter how much we try to control and grade exposure, particularly when conducted in the field, it seems the "graded" intentions of systematic desensitisation can always be sabotaged, as fate conspires to flood.

\title{
The church of St Leopold, Vienna
}

In 1907 the Lower Austrian provincial institution for the care and treatment of mental and neuropathological patients, am Steinhof, was opened. Situated on the slopes of Gallitzinberg, a hill in the 14th district of Vienna, the imposing complex of buildings was designed by the architect Otto Wagner. It had two departments, one for acute and one for long-term patients; male and female patients were treated separately so there were four units.

Since 1921 the hospital has been the Provincial Mental Hospital for Vienna, known as Psychiatrisches Krankenhaus/Baumgartner Höhe (PKHBH). About 25 years ago the departments were reduced in size and the separation between acute and long-term patient units was discontinued. PKH now treats about 5,000 in-patients annually.

The church of St Leopold, situated in the centre of the hospital grounds, was built between 1905 and 1907 and was one of the major works of Otto Wagner. It is considered one of the most important architectural examples of art nouveau.

The four angels above the main entrance of the church were created by the Hungarian sculptor Othmar Schimkowitz.

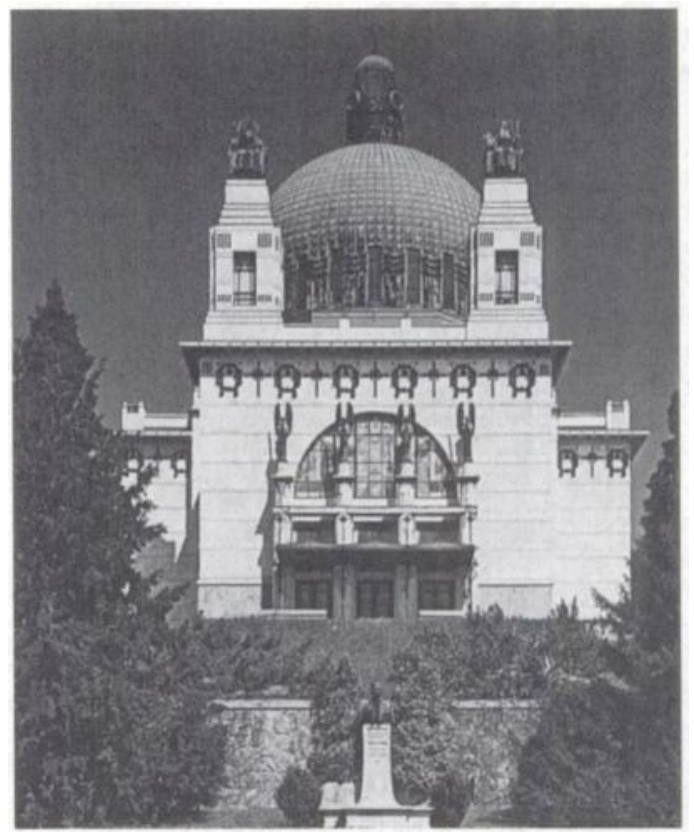

Psychiatric Bulletin (1993), 17, 761

\section{Buried Grief}

Living in the mirrors of lost time,

He believes all time is lost

And spent.

All sadness eternal,

All joy an accident,

Unrecorded and without witness.
Pity the man with buried grief, But offer him no comfort, No relief.

He alone can disinterr

The gall within the stomach's soul.

Teach him to remember.

DAVID NORRIS 